\title{
REFLEXÕES A PARTIR DA PERCEPÇÃO DOS DISCENTES SOBRE INCLUSÃO E COTAS PARA ESTUDANTES COM DEFICIÊNCIAS NO ENSINO SUPERIOR
}

\author{
REFLEXIONES DE LA PERCEPCIÓN DE LOS ESTUDIANTES SOBRE INCLUSIÓN \\ Y CUOTA PARA ESTUDIANTES CON DISCAPACIDADES EN LA EDUCACIÓN \\ SUPERIOR
}

\author{
REFLECTIONS FROM THE PERCEPTION OF STUDENTS ON INCLUSION AND \\ QUOTA FOR STUDENTS WITH DISABILITIES IN HIGHER EDUCATION
}

\author{
Ana Cristina SILVA SOARES ${ }^{1}$ \\ Daniele Kelly LIMA DE OLIVEIRA ${ }^{2}$ \\ Maria Gorete DE SOUSA ${ }^{3}$
}

\begin{abstract}
RESUMO: Este artigo analisa como a inclusão no ensino superior, sendo marcada por desigualdades e ideias equivocadas, vem comprometendo até os dias atuais o acesso e a permanência dos estudantes, na busca por cursos de graduação. Os dados empíricos permitiram a construção de pressupostos para uma pesquisa de abordagem qualitativa, documental e quantitativa, com estudantes do primeiro ao oitavo período do curso de Pedagogia, da Universidade Estadual Vale do Acaraú (UVA), no município de Sobral, Ceará. Foram instrumentos de coleta de dados: análise de documentos e questionário para apreensão da realidade. Os documentos são: Política Nacional de Educação Especial na Perspectiva da Educação Inclusiva, de 2008; Lei 16.197, de 2017, que dispõe sobre a instituição do Sistema de Cotas nas Instituições de Ensino Superior do Estado do Ceará; Resolução do Conselho Nacional de Educação - CNE/Conselho Pleno - CP 02, de 2015; Resumo Técnico: Censo da Educação Superior 2016; e Projeto Pedagógico do curso de Pedagogia da UVA, de 2018. As informações obtidas foram analisadas por meio de tratamento estatístico, análise de conteúdo e contribuições teóricas de autores como Booth e Ainscow, Mittler, Marchesi, Behring, Moehlecke, Ribeiro e Tonet. Os resultados evidenciam sobre os discentes "o que pensam" no âmbito da formação inicial, do curso de Pedagogia e que podem colaborar na construção das relações sociais e pedagógicas e de algumas ações para se elaborarem políticas institucionais que auxiliem a inclusão de estudantes com deficiências no Ensino Superior.
\end{abstract}

PALAVRAS-CHAVE: Curso de pedagogia. Cotas. Inclusão.

RESUMEN: Este artículo analiza cómo la inclusión en la educación superior, marcada por las desigualdades y los conceptos erróneos, ha comprometido hasta el día de hoy el acceso y la permanencia de los estudiantes en la búsqueda de cursos de pregrado. Los datos empíricos permitieron la construcción de supuestos para una investigación de enfoque cualitativo, documental y cuantitativo, con estudiantes del primer al octavo período del curso de Pedagogía, en la Universidad Estatal Vale do Acaraú (UVA), en Sobral, Ceará. Los

\footnotetext{
${ }^{1}$ Universidade Estadual Vale do Acaraú (UVA), Sobral - CE - Brasil. Docente do Curso de Pedagogia. ORCID: https://orcid.org/0000-0002-0211-965X. E-mail: acsilvasoares@gmail.com

${ }^{2}$ Universidade Estadual Vale do Acaraú (UVA), Sobral - CE - Brasil. Docente do Curso de Pedagogia. ORCID: https://orcid.org/0000-0002-8891-7328. E-mail: dankel28@yahoo.com.br

${ }^{3}$ Universidade Estadual Vale do Acaraú (UVA), Sobral - CE - Brasil. Docente do Curso de Pedagogia. ORCID: https://orcid.org/0000-0002-3718-8145. E-mail: magoretes@gmail.com
}

Doxa: Rev. Bras. Psico. e Educ., Araraquara, v. 21, n. 2, p. 226-240, jul./dez. 2019. e-ISSN: 2594-8385 
instrumentos de recolección de datos fueron: análisis de documentos y cuestionarios para aprehender la realidad. Los documentos son: Política nacional sobre educación especial en la perspectiva de la educación inclusiva, 2008; Ley 16.197, 2017, que establece el establecimiento del Sistema de Cuotas en las Instituciones de Educación Superior del Estado de Ceará; Resolución del Consejo Nacional de Educación - CNE / Consejo Completo - CP 02, 2015; Resumen técnico: Censo de educación superior 2016; y Proyecto Pedagógico del Curso de Pedagogía UVA, 2018. La información obtenida se analizó a través del tratamiento estadístico, análisis de contenido y contribuciones teóricas de autores como Booth y Ainscow, Mittler, Marchesi, Behring, Moehlecke, Ribeiro y Tonet. Los resultados muestran sobre los estudiantes "lo que piensan" en el ámbito de la formación inicial, el curso de Pedagogía y que pueden colaborar en la construcción de las relaciones sociales y pedagógicas y de algunas acciones para elaborar políticas institucionales que ayuden a la inclusión de estudiantes con discapacidad en el Enseñanza superior.

PALABRAS CLAVE: Curso de Pedagogía. Cuotas. Inclusión.

ABSTRACT: This article analyzes how the inclusion in higher education, being marked by inequalities, and mistaken ideas, has been compromising until the present day the access and the permanence of the students, in the search for undergraduate courses. The empirical data allowed the construction of assumptions for a qualitative, documental and quantitative approach, with students from the first to the eighth period of the Pedagogy course, from the Vale do Acaraú State University (UVA), in the municipality of Sobral, Ceará. They were instruments of data collection: document analysis and questionnaire for the apprehension of reality. The documents are: National Policy on Special Education in the Perspective of Inclusive Education, 2008; Law 16,197, of 2017, provides for the institution of the System of Quotas in Higher Education Institutions of the State of Ceará; Resolution of the National Education Council - CNE/Plenary Council - PC 02, of 2015; Technical Summary: Census of Higher Education 2016; and Pedagogical Project of the course of Pedagogy of the UVA, of 2018. The information obtained was analyzed through statistical treatment, content analysis and theoretical contributions from authors such as Booth and Ainscow, Mittler, Marchesi, Behring and Boschetti, Moehlecke, Ribeiro and Tonet. T The results show that the students "what they think" in the context of initial formation, of the Pedagogy course, and that can collaborate in the construction of social and pedagogical relations, as well as in the construction of some actions to elaborate institutional policies that collaborate with the inclusion of students with disabilities in Higher Education.

KEYWORDS: Course of Pedagogy. Quotas. Inclusion.

\section{Introdução}

A temática da inclusão no ensino superior deve ser pensada a partir da ideia da oferta de um sistema de ensino para todos, em equidade de condições e possibilidades de aprendizagem, atendendo às necessidades educacionais específicas dos alunos com deficiência (STAINBACK; STAINBACK, 1999; SANCHEZ, 2005). Nesse sentido, surgem questões como: O que é inclusão? O que é inclusão de alunos com deficiência? Quais as percepções dos estudantes que estão na formação inicial sobre a possibilidade das políticas 
afirmativas? O que os estudantes de um curso de graduação sabem sobre as políticas de ações afirmativas?

O objetivo do presente trabalho ${ }^{4}$ é analisar como a inclusão no ensino superior, sendo marcada por desigualdades e ideias equivocadas, vem comprometendo até os dias atuais o acesso e a permanência dos estudantes, na busca por cursos de graduação. No Brasil, a Lei das Cotas, n. ${ }^{\circ} 12.711$, foi aprovada em agosto de 2012, como política pública de ação afirmativa no Ensino Superior, após mais de uma década de debate e com muitas controvérsias.

Nossa base teórica de análise ancora-se nos pressupostos e pesquisas de estudiosos da área, como Stainback e Stainback (1999), Booth e Ainscow (2002), Mittler (2003), Marchesi (2004) e Sanchez (2005), a concepção de inclusão no ensino superior em Parra e Infante (2006), Siqueira e Santana (2010), Castanho e Freitas (2005), Rodrigues (2004), as reflexões acerca das questões gerais que envolvem as políticas públicas de inclusão e cotas com Behring e Boschetti (2011), Tonet (2005), Moehlecke (2002), Gonçalves e Silva (2003) e Ribeiro (2018).

Ao discutir sobre a inclusão, Booth e Ainscow (2002) estabelecem uma associação entre três dimensões, inter-relacionadas entre si: cultural, política e prática. A dimensão cultural refere-se ao estabelecimento de uma cultura baseada em princípios e valores inclusivos, ou seja, uma cultura inclusiva. A cultura inclusiva no ambiente escolar propõe o desenvolvimento de valores que mobilizem as pessoas a pensar, a compartilhar e a se respeitar. Propõe o estímulo à criação de uma comunidade escolar acolhedora, receptiva, colaborativa e que incentive o êxito dos alunos. A dimensão política trata da escola para todos, organizando o apoio à diversidade; isso quer dizer que a inclusão precisa ser considerada em todos os planos da escola, bem como nas atividades, estratégias e outras formas de apoio com os princípios inclusivos. A dimensão política favorece ao poder público vigente criar uma legislação própria, fortalecendo os sistemas de ensino para atender às demandas sociais existentes. Finalmente, a dimensão prática procura organizar a aprendizagem, mediante a mobilização de recursos pedagógicos e didáticos. Essa dimensão efetiva a inclusão, propondo que as atividades de sala de aula e extrassala envolvam todos os alunos, considerando suas condições de aprendizagem, necessidades e experiências. Em síntese, para que a inclusão aconteça é necessário: criar uma cultura inclusiva; implementar uma política inclusiva; e desenvolver uma prática inclusiva. Assim, de acordo com os autores, a mudança necessária para tornar a escola inclusiva passa pelas três dimensões: cultural, política e prática.

${ }^{4}$ É resultado de um projeto de pesquisa, em andamento, intitulado "Inclusão, acessibilidade, deficiências, práticas pedagógicas e formação de professores: maneiras de pensar e de agir de professores e alunos da educação básica e do ensino superior do município de Sobral - CE”. 
Desse modo, um dos pontos difíceis para se superar são as condições de permanência de alunos com deficiência para que haja inclusão na Educação. Por isso, o que se propor como condições de equidade no campo educacional do Ensino Superior?

\section{Para que as políticas públicas de ações afirmativas no ensino superior?}

Adentrar no terreno das políticas públicas demanda uma compreensão delas tendo como base de análise os diversos campos que compõem a totalidade social, sejam estes políticos, econômicos, sociais e/ou culturais, considerando-as como resultado de múltiplas determinações.

Trata-se de analisar as políticas sociais como processo e resultado de relações complexas e contraditórias que se estabelecem entre Estado e sociedade civil, no âmbito dos conflitos e luta de classes que envolvem o processo de produção e reprodução do capitalismo, nos seus grandes ciclos de expansão e estagnação, ou seja, problematiza-se o surgimento e o desenvolvimento das políticas sociais no contexto da acumulação capitalista e da luta de classes, com a perspectiva de demonstrar seus limites e possibilidades (BEHRING; BOSCHETTI, 2006, p. 304).

Advindas do campo maior das políticas sociais, podemos percebê-las em seus desafios e potencialidades, além de serem instrumentos institucionais forjados com o objetivo de assegurar a cada indivíduo as condições materiais de uma vida digna, as políticas públicas também são apresentadas com o objetivo de atender às demandas do próprio sistema econômico atual, que tem por base a divisão social.

Compreendem o conjunto de decisões e ações propostas geralmente por uma instância do Estado, em uma determinada área, de maneira discricionária ou com a sociedade civil. Esse entendimento nos dá elementos para analisarmos os desafios e as potencialidades das políticas públicas de inclusão, particularmente em seu caráter de ações afirmativas.

As políticas públicas de recorte social (usualmente entendidas como as de educação, saúde, previdência, habitação, saneamento etc.), referem-se a ações que determinam o padrão de proteção social implementado pelo Estado, voltadas, em princípio, para a redistribuição dos benefícios sociais visando à diminuição das desigualdades estruturais produzidas pelo desenvolvimento socioeconômico.

Assim, vistas como ações afirmativas dos diversos grupos sociais que se encontram à margem da sociedade, seja, por exemplo, quanto às questões étnico-raciais, de gênero e/ou das pessoas com deficiência, essas políticas públicas necessitam ser pensadas diretamente com relação ao conceito de democracia que vivemos e àquela que buscamos alcançar. 
Moehlecke (2002) apresenta um panorama histórico e conceitual acerca das ações afirmativas no mundo e no Brasil, com o objetivo de nos levar a uma reflexão sobre as controvérsias que envolvem essa temática como política pública eficaz no combate à discriminação e desigualdade dos diversos grupos beneficiados por ela, em sua forma de cotas sociais.

As ações afirmativas têm relação direta com o conceito de democracia, pois, como demonstra Tonet (2005), vivemos uma concepção parcial de democracia limitada, ligada a uma perspectiva de emancipação política, que circunscreve seus limites a uma pequena parcela da sociedade, enquanto a forma de democracia de que necessitamos, para que os grupos excluídos possam ser realmente incluídos, está ligada a um processo de emancipação humana, configurando uma sociabilidade cujo fundamento é o bem de todos os envolvidos, sendo assim plena e ilimitada.

Embora as ações afirmativas tenham como marco inicial as políticas de eliminação das leis segregacionais, implementadas pelo governo norte-americano dos Estados Unidos, em 1960, e na Europa, em 1976, como estratégias mistas (voluntárias e obrigatórias), no Brasil, como aponta Munanga (1996), essas ações iniciaram respondendo às reivindicações dos movimentos sociais, ainda com características de medidas redistributivas e assistenciais.

A ação afirmativa é uma forma de planejar e promover os grupos que têm sido excluídos histórica, política e economicamente da sociedade, tendo como consequência sua permanência em situação de subalternidade e negação de acesso a bens culturais, econômicos e sociais, por exemplo, o emprego e a educação. Tais grupos são algumas vezes classificados como "minoria", mas quantitativamente fazem parte da maior parcela que compõem a sociedade.

A política de cotas, por exemplo, enquadra-se nas estratégias mistas, pois envolvem o mercado de trabalho e o sistema educacional, e trata de experiências que têm por objetivo "a ideia de redistribuir uma igualdade que foi rompida, ou que nunca existiu" (MOEHLECKE, 2002, p. 200).

Em seus estudos acerca das questões étnico-raciais a filósofa Djamila Ribeiro (2018) conceitua as cotas como um instrumento de reparação social, que combate uma história de exclusão, por exemplo, quando se trata da população negra:

Cota é uma modalidade que visa diminuir as distâncias, no caso das universidades, na educação superior. Mesmo sendo a maioria no Brasil, a população negra é muito pequena na academia. E por quê? Porque o racismo institucional impede a mobilidade social e o acesso da população negra a esses espaços (RIBEIRO, 2018, p. 73). 
Observando o grupo das pessoas com deficiência, o cenário não é muito diferente. Segundo os resultados do Censo Escolar (INSTITUTO NACIONAL DE ESTUDOS E PESQUISAS EDUCACIONAIS ANÍSIO TEIXEIRA, 2012; 2006), apresenta que o País ampliou em 17,1\% o número das matrículas em educação especial na rede pública em relação ao ano anterior, passando de 700.624 matrículas em 2006 para 820.433 em 2012. No âmbito do ensino superior, no mesmo período, um total de 6.960 para 27.323 matrículas de alunos com alguma deficiência em Instituições de Ensino Superior (IES). Nota-se que está havendo um crescimento desde a educação básica à educação superior.

$\mathrm{O}$ acesso de pessoas com deficiência vem aumentando, portanto, verificam-se algumas medidas de inclusão de alunos com deficiência no sistema público de ensino (da educação superior), o qual visa à ampliação de vagas na busca pela crescente democratização das instituições de ensino público brasileiras.

No Censo referente ao Ensino Superior, de 2016, observa-se o registro de "12.290 ingressantes de graduação declarados como deficientes, com transtorno global do desenvolvimento ou altas habilidades/superdotação, o que corresponde a $0,4 \%$ do total de ingressantes. Cumpre registrar que um mesmo vínculo discente, no caso, o de ingressante, pode apresentar mais de um tipo de declaração. Entre as especificações mais comuns, 35,8\% aparecem como deficientes físicos, 29,8\% registram baixa visão; e 13,2\%, deficiência auditiva". Um dado de

[...] 35.891 matrículas de graduação (ou $0,4 \%$ do total de matrículas) declaradas com algum tipo de deficiência, transtorno global do desenvolvimento ou altas habilidades/superdotação. No conjunto das declarações, Deficiência Física (12.775 ou 34,8\%), Baixa Visão (11.028 ou $30,0 \%)$ e Deficiência Auditiva (5.051 ou 13,7\%) [...] (INSTITUTO NACIONAL DE ESTUDOS E PESQUISAS EDUCACIONAIS ANÍSIO TEIXEIRA, 2016, p. 27-34).

Ao analisar a resistência que se encontra ainda na universidade, com relação à política de cotas, a pesquisadora Petronilha Beatriz Gonçalves e Silva (2003) lança luzes sobre algumas questões que cercam essa problemática. Trazendo exemplos dos casos da Universidade Estadual da Bahia (UEB) e da Universidade Estadual do Rio de Janeiro (UERJ), que, ao propor reserva de vagas para negros, tendo como critério primeiro a aprovação no concurso vestibular, sofreram desqualificação e processos jurídicos da parte dos que se sentem prejudicado, e tentam impedi-las de dar continuidade à tão importante decisão política (GONÇALVES E SILVA, 2003, p. 46).

Para a pesquisadora, esses comportamentos de resistência às políticas de cotas sinalizam um pensamento elitista que revela, de forma agressiva ou benevolente, rejeição 
explícita ou camuflada aos negros, aos grupos que historicamente tem sido negado o lugar de protagonista de sua própria história. Esse argumento, geralmente, baseado no pressuposto de uma suposta democracia plena, defende que tais políticas públicas não podem ser aceitas por configurar um caráter assistencialista, portanto segregador, uma vez que nessa democracia "haveria" a igualdade de oportunidades entre os mais diversos grupos.

Entretanto, como mencionado anteriormente, a democracia que se advoga como plena, na verdade, é apenas parcial. As cotas como ações afirmativas representam a materialização de um movimento reparatório, de combate às desigualdades que atingem certos grupos, e a integração de todos os grupos que compõem a sociedade de forma geral, promovendo, assim, a busca por um real processo de inclusão.

Em 2008, o Governo Federal assume um papel relevante com a divulgação da proposta da Política Nacional de Educação Especial na Perspectiva da Educação Inclusiva, defendendo a inclusão como uma ação política, social, pedagógica e cultural. Nesse campo, surge a cobrança pela inclusão de alunos com deficiência em sistemas de ensino. Tal proposta determina a garantia do direito de todos os alunos compartilharem do mesmo sistema de ensino, sem nenhuma forma de discriminação, e assumindo "a concepção dos direitos humanos articulados à igualdade e à diferença como um valor indissociável" (BRASIL, 2008).

As condições de ingresso, de acessibilidade e de permanência de alunos com deficiência são fatores essenciais para que haja inclusão no Ensino Superior. Reconhecer as necessidades e as habilidades dos distintos alunos com deficiência, criando mecanismos pedagógicos efetivos para serem aplicados em sala de aula, garantindo, também, o acesso aos recursos didáticos e pedagógicos adequados são requisitos fundamentais para que ocorra inclusão na perspectiva de todos os alunos com deficiência (RODRIGUES, 2004), bem como a questão de acessibilidade.

Nos últimos anos, a acessibilidade segue um desenho universal no que diz respeito aos ambientes, meios de transporte e utensílios que devem ser projetados para todos, e não apenas para pessoas com deficiência. Para Sassaki (2002), o conceito começou a ser utilizado, principalmente, nos assuntos ligados à reabilitação, saúde, educação, transporte, mercado de trabalho e ambientes físicos internos e externos. O autor elaborou alguns tipos de acessibilidade: Acessibilidade arquitetônica: sem barreiras ambientais físicas nas escolas, nas empresas, nas residências, nos edifícios públicos, nos centros de convenção, nos espaços urbanos, nos equipamentos urbanos e nos meios de transporte individual ou coletivo; Acessibilidade comunicacional: sem barreiras na comunicação interpessoal - face a face, língua de sinais, linguagem corporal, linguagem gestual e outros; na comunicação escrita - 
jornal, revista, livro, carta, apostila e outros, incluindo textos em Braile e textos com letras ampliadas, notebook e outras tecnologias assistivas para comunicação; e na comunicação virtual - acessibilidade digital; entre outros. Santos (2003, p. 56) enfatiza que

[...] as pessoas e os grupos sociais têm o direito a ser iguais, quando a diferença os inferioriza; e o direito a ser diferentes quando a igualdade os descaracteriza. Por isso, a necessidade de uma igualdade que reconheça as diferenças e de uma diferença que não produza, alimente ou reproduza as desigualdades.

Por isso, o aluno com deficiência precisa ter acesso a apoios pedagógicos, por exemplo, um cego ter acesso a texto em Braille para conseguir fazer a leitura com os demais alunos de sala de aula.

Em 2018, o curso pesquisado passou por uma reformulação curricular, cuja proposta segue as orientações referentes às Diretrizes Nacionais Curriculares para o curso de Pedagogia, de 2015. Nesse novo currículo, entre as várias alterações realizadas, propõe-se conhecer e analisar princípios, contextos, fundamentos da inclusão escolar e bases legais da educação inclusiva e da educação especial. Desse modo, sugeriram-se três componentes curriculares: Educação Inclusiva (obrigatória), Educação Especial e Práticas de ensino em Educação Inclusiva (optativas).

Marchesi (2004) enfatiza que diferentes contextos educacionais e políticos podem determinar concepções distintas de inclusão. Para o autor, o contexto político refere-se aos aspectos históricos, culturais e de tradição do sistema de ensino de cada país, considerando que cada qual tem uma história, uma cultura, uma ideologia e uma tradição educativa, as quais condicionam a incidência das mudanças e a resposta que é dada ao sistema educativo. Ou seja, a inclusão nos vários sistemas de ensino, no sentido de se obter uma educação de qualidade e benéfica para todos.

No aspecto referente aos fatores pragmáticos à inclusão, o trabalho de Karagiannis, Stainback e Stainback (1999) e Stainback (2006) aborda os benefícios da educação inclusiva. Há alguns aspectos envolvendo alunos, professores e a comunidade em geral que são enfatizados, bem como as atitudes positivas e a capacitação de professores. Esses autores afirmam:

[...] nas salas de aula... todas as crianças enriquecem-se por terem a oportunidade de aprender umas com as outras, desenvolvem-se para cuidar umas das outras e conquistam as atitudes, as habilidades e os valores necessários para a nossa comunidade apoiarem a inclusão de todos os cidadãos [...] as atitudes positivas com relação aos alunos com deficiência desenvolvem-se quando são proporcionadas orientação e direção por parte 
dos adultos em ambientes integrados [...] A colaboração permite-lhes a consulta um ao outro [...] (KARAGIANNIS; STAINBACK; STAINBACK, 1999, p. 23-26).

Portanto, consideramos que o sucesso da inclusão envolve um conjunto de elementos: alunos; professores; comunidade; apoio, flexibilidade; recursos; atualização; colaboração; e planejamento, conjuntura política, econômica e social.

Para Mantoan (2003), a cooperação, as autonomias intelectual e social e a aprendizagem ativa são condições que propiciam o desenvolvimento global de todos os professores, no processo de aprimoramento profissional. Como se considera o professor uma referência para o aluno, e não apenas um mero instrutor, a formação enfatiza a importância de seu papel, tanto na construção do conhecimento como na formação de atitudes e valores do cidadão. Assim sendo, a formação vai além dos aspectos instrumentais de ensino.

Os trabalhos de Siqueira e Santana (2010), Parra e Infante (2006), Castanho e Freitas (2005) e Rodrigues (2004), no tocante à concepção de inclusão na educação superior, têm mostrado algumas práticas que auxiliam na eliminação de barreiras de comunicação e de informação, abordando as práticas educacionais tanto no ingresso e na permanência na universidade quanto no trabalho de formação dos professores em serviço; além disso, evidenciam o foco para os aspectos que dizem respeito aos alunos e suas relações cotidianas no ambiente universitário.

Os dados empíricos permitiram a construção de uma pesquisa de abordagem qualitativa, documental e quantitativa, com estudantes do primeiro ao oitavo período do curso de Pedagogia, da Universidade Estadual Vale do Acaraú (UVA), no município de Sobral, Ceará. A coleta de dados envolveu aplicação de questionários e análise de documentos. Para análise dos dados optou-se pelo estudo de Bardin (2009), a análise de conteúdo sobre o entendimento e percepções dos discentes no ambiente universitário acerca do conceito de inclusão e cotas para estudantes com deficiência no ambiente acadêmico.

A escolha e a observação dos documentos consistem na definição do corpus de análise, sendo os seguintes: Política Nacional de Educação Especial na Perspectiva da Educação Inclusiva, de 2008; Lei n. ${ }^{\circ}$ 16.197, de 2017, dispõe sobre a instituição do Sistema de Cotas nas Instituições de Ensino Superior do Estado do Ceará; Resolução Conselho Nacional de Educação - CNE/Conselho Pleno - CP n. ${ }^{\circ}$ 02, de 2015; Resumo Técnico: Censo da Educação Superior 2016; e Projeto Pedagógico do curso de Pedagogia da Universidade Estadual Vale do Acaraú, de 2018.

Ressalta-se um dos itens do questionário, no que se diz respeito às respostas dos estudantes sobre o sistema de cotas da UVA para candidatos de cotas sociais, negros, indígenas e/ou pessoas com deficiências, na tabela a seguir: 
Tabela 1 - Você concorda com sistema de cotas para candidatos de cotas sociais, negros, indígenas e/ou pessoas com deficiências:

\begin{tabular}{c|c|c}
\hline Tipos de Respostas & Períodos (08) & Percentual (\%) \\
\hline Sim & 305 & 78,41 \\
\hline Não & 60 & 15,42 \\
\hline Sem resposta & 20 & 5,14 \\
\hline Duas opções & 04 & 1,03 \\
\hline Total & 389 & 100 \\
\hline
\end{tabular}

Fonte: Elaboração das autoras.

Os dados supra evidenciam a percepção do estudante na concordância pelas cotas. Essa situação necessitaria de uma análise para se compreender que o modelo de cotas atenderia à demanda para o curso e, também, o que realmente os estudantes sabem sobre essas políticas de ações afirmativas?

É importante ressaltar que a universidade se configura como um espaço de construção e trocas de conhecimento, além de convívio social, e é responsável pela promoção da cidadania e, como tal, tem o dever de oportunizar e incentivar uma educação para todos. Castanho e Freitas (2005) revelam que o convívio em uma comunidade acadêmica possibilita às pessoas com deficiências um projeto de vida concretizado, principalmente quando o convívio e as trocas se fortalecem a partir do apoio mútuo. A seguir, algumas considerações sobre o instrumento de coleta de dados da pesquisa, com foco na análise de conteúdo, acerca da inclusão de alunos com deficiência na universidade.

No que se refere ao entendimento e percepções dos estudantes acerca da inclusão e cotas para alunos com deficiências, apontam-se algumas categorias de análise de conteúdos por meio do estudo e observação de documentos, como a Lei de Diretrizes e Bases da Educação (BRASIL, 1996) e o Projeto Pedagógico do Curso (PPC) de Pedagogia (2018), entre outros citados anteriormente, favorecendo, assim, as políticas de inclusão nesse universo, como a questão das cotas na universidade. O PPC contém os seguintes eixos: pedagogia: identidade profissional e formação social histórica; educação e inclusão social; educação, trabalho e afetividade; e ensino e aprendizagem. 
Cabe salientar, no caso do Estado do Ceará, a Lei n. ${ }^{\circ}$ 16.197, de 17 de janeiro de 2017, que dispõe sobre a instituição do Sistema de Cotas nas Instituições de Ensino Superior do Estado do Ceará e estabeleceu o ano de 2018 para a efetivação da inclusão das cotas. A Universidade Estadual Vale do Acaraú (UVA) deu início ao ingresso por cotas em 2018. Um salto um pouco tardio, uma vez que essa instituição de ensino superior estava com seis anos de atraso em relação à lei nacional. A Lei Estadual estabelece a cota: a) para alunos de escolas públicas; e b) para pessoas com deficiências, mas a UVA implantou as cotas somente para o primeiro caso. Neste momento, faz-se necessário indagar: A UVA está preparada para inclusão? Como esse processo será concretizado? Que ações devem ser implantadas para o curso de pedagogia dessa instituição desenvolver suas ações pedagógicas nesse novo quadro?

Consideram-se neste trabalho, os seguintes aspectos previstos no questionário: Identificação - Onde você reside atualmente? Solicita-se o dado sobre município e Estado; Informações econômicas - Qual a situação legal da casa em que você mora?; Informações escolares - Ano em que você concluiu o Ensino Médio; Informações socioculturais - Quantos livros, em média, você lê por ano, excetuando-se os livros didáticos?; Informações de inclusão e acessibilidade - Você já ouviu falar de acessibilidade?; Você conhece a Política Nacional de Educação Especial na perspectiva da Educação Inclusiva, 2008? Essas indagações buscam trazer compreensões sobre o contexto social, cultural e político do estudante de graduação, que muitas vezes refletem o seu modo de agir durante a formação inicial, na qual deveria oportunizar dimensões articuladas ao conhecimento e ao fazer pedagógico sobre aspectos da inclusão e uso de cotas no ensino superior. Para Castanho e Freitas (2005) essa formação inicial precisa valorizar a diversidade em todos os espaços, exigindo uma mudança de paradigma educacional no sentido da inclusão como processo que reconhece e respeita diferentes identidades sem discriminar ninguém.

Por sua vez, Mantoan (2003) aponta que a inclusão implica uma mudança de perspectiva educacional, pois não atinge apenas estudantes com deficiência e os que apresentam dificuldades de aprender, mas todos os demais, para que possam obter sucesso durante a formação acadêmica, de forma geral.

Para Siqueira e Santana (2010), observa-se a era da diversidade, na qual não cabe mais discriminar e excluir, pois o reconhecimento e a inclusão de grupos que, em geral, foram excluídos, sejam étnico-raciais, de gênero e/ou pessoas com deficiência, podem representar um avanço significativo para a instauração de uma sociedade plenamente democrática. 


\section{Considerações finais}

Diante do exposto, para o alcance do objetivo deste estudo, buscamos analisar o entendimento e as percepções dos discentes no ambiente universitário acerca do conceito de inclusão e cotas para estudantes com deficiência no ambiente acadêmico. Nesse aspecto, é importante considerar que, na formação inicial deste estudante, além da construção do conhecimento, faz-se necessária a formação de atitudes e valores do cidadão. Também, podem auxiliar nessa construção práticas educacionais inclusivas que favoreçam os aspectos que dizem respeito aos alunos com deficiências e às relações cotidianas no ambiente universitário.

No tocante às resistências, por parte dos estudantes, quanto ao processo de inclusão social na forma de ações afirmativas, por exemplo, a política de cotas, correspondendo ao percentual de $15,42 \%$, entendemos que essa questão ainda está envolvida por muitas controvérsias, que são resultado, entre outros fatores, de uma estrutura social desigual, que legitima as desigualdades como resultado "natural" da vida, negando que tal ação é na verdade um desdobramento histórico de um processo de divisão social de classes, expropriação econômica e negação de acesso aos bens culturais e econômicos por parte da parcela mais fragilizada da população, os grupos que, em geral, têm sido excluídos, sejam étnico-raciais, de gênero e/ou pessoas com deficiência.

Outra problemática que reforça essa visão de rejeição à política de cotas é a concepção que temos de democracia, que nos leva a uma visão distorcida de inclusão social, pois, como vivemos uma versão parcial, entende-se que bastaria que as pessoas tivessem acesso às mesmas oportunidades, por exemplo, à educação e ao emprego. Entretanto, ao compreendermos que alguns grupos foram historicamente excluídos, conseguimos perceber a necessidade das políticas públicas que garantam acesso e permanência em todas as instâncias da sociedade.

Isso não retira a necessidade de, mesmo numa situação de democracia parcial, lutarmos pelas condições mínimas que garantam a dignidade da pessoa humana em todos os espaços da sociedade.

\section{REFERÊNCIAS}

BARDIN, L. Análise de conteúdo. Lisboa: Edições 70, 2009.

BEHRING, E. R.; BOSCHETTI, I. Política social: fundamentos e história. São Paulo: Cortez, 2006. 
BOOTH, T.; AINSCOW, M. Index on inclusive: developing learning and participation in schools. Bristol: CSIE, 2002.

BRASIL. Lei n. ${ }^{\circ}$ 9.394, de 20 de dezembro de 1996. Lei de Diretrizes e Bases da Educação Nacional, 1996. Disponível em: http://www2.camara.gov.br. Acesso em: 21 jan. 2010.

BRASIL. Ministério da Educação. Portaria n. 948/2007. Política Nacional de Educação Especial na Perspectiva da Educação Inclusiva. Brasília, 2008.

BRASIL. Ministério da Educação. Resolução CNE/CP n. ${ }^{\circ}$ 02, de $1 .^{\circ}$ de julho de 2015. Define as Diretrizes Curriculares Nacionais para a formação inicial em nível superior (cursos de licenciatura, cursos de formação pedagógica para graduados e cursos de segunda licenciatura) e para a formação continuada. Diário Oficial [da] República Federativa do Brasil, Brasília, DF, 2015. Disponível em: http://portal.mec. gov.br/docman/agosto-2017-pdf/70431-res-cnecp-002-03072015-pdf/file. Acesso em: 16 maio 2019.

CASTANHO, D. M.; FREITAS, S. N. Inclusão e prática docente no ensino superior. Revista Educação Especial, Santa Maria, n. 27, p. 85-92, 2005. Disponível em:

http://coralx.ufsm.br/revce/.ceesp/2006/01.htm. Acesso em: 20 jul. 2007.

CEARÁ. Lei n. ${ }^{\circ}$ 16.197, 17 de janeiro de 2017. Dispõe sobre a instituição do Sistema de Cotas nas Instituições de Ensino Superior do Estado do Ceará. Diário Oficial do Estado, Fortaleza, Série 3, ano 9, n. 013, p. 1, 18 jan. 2017.

GONÇALVES E SILVA, P. B. Negros na universidade e produção do conhecimento. Educação e ações afirmativas: entre a injustiça simbólica e a injustiça econômica, Brasília: Instituto Nacional de Estudos e Pesquisas Educacionais Anísio Teixeira, 2003.

INSTITUTO NACIONAL DE ESTUDOS E PESQUISAS EDUCACIONAIS ANÍSIO TEIXEIRA. Censo Educacional, 2006. 2007. Disponível em: http://www.inep.gov.br/ basica/censo/default.asp. Acesso em: 02 fev. 2010.

INSTITUTO NACIONAL DE ESTUDOS E PESQUISAS EDUCACIONAIS ANÍSIO TEIXEIRA. Censo Educacional, 2012. 2013. Disponível em: http://www.inep.gov.br/ basica/censo/default.asp. Acesso em: 30 mar. 2016.

INSTITUTO NACIONAL DE ESTUDOS E PESQUISAS EDUCACIONAIS ANÍSIO TEIXEIRA. Resumo Técnico: Censo da Educação Superior 2016. Brasília: INEP, 2018.

KARAGIANNIS, A.; STAINBACK, W.; STAINBACK, S. Fundamentos do Ensino Inclusivo. In: STAINBACK, S.; STAINBACK, W. Inclusão: um guia para educadores. Porto Alegre: Artmed, 1999. p. 35-47.

MANTOAN, M. T. E. Inclusão escolar: o que é? por quê? como fazer?. São. Paulo: Moderna, 2003.

MARCHESI, A. Da linguagem da deficiência às escolas inclusivas. In: MARCHESI, A.; COLL, C.; PALACIOS, J. Desenvolvimento psicológico e educação: transtornos de desenvolvimento e necessidades educativas especiais. Porto Alegre: Artmed, 2004. v. 3, p. 15-30. 
MENDES, E. G. A radicalização do debate sobre inclusão no Brasil. Revista Brasileira de Educação, São Paulo, v. 11, n. 33, p. 387-405 set./dez. 2006.

MITTLER, P. Educação inclusiva: contextos sociais. Porto Alegre: Artmed, 2003.

MOEHLECKE, S. Ação afirmativa: história e debates no Brasil. Cadernos de Pesquisa, São Paulo, n. 117, p. 197-217, nov. 2002.

MUNANGA, K. O anti-racismo no Brasil. In: MUNANGA, K. (Org.). Estratégias e políticas de combate à discriminação racial. São Paulo: Edusp, 1996.

PARRA, D. J. L.; INFANTE, G. R. Consideraciones en la intervención psicopedagógica en el alumnado universitario con discapacidad. Revista La Escuela Universitária de Magistério de Toledo, Toledo, ano 31, n. 16, p. 241-256, jan./dez. 2006.

RIBEIRO, D. Quem tem medo do feminismo negro? São Paulo: Companhia das Letras, 2018 .

RODRIGUES, D. A inclusão na universidade: limites e possibilidades da construção de uma universidade inclusiva. Revista de Educação Especial UFSM, Santa Maria, n. 23, 2004. Disponível em: http://www.ufsm.br/ce/revista/ceesp. Acesso em: 5 set. 2010.

SANCHEZ, P. A. A educação inclusiva: um meio de construir escolas para todos no século XXI. Revista de Educação Especial, Brasília, 2005. Disponível em: http://portal.mec. gov.br/seesp/arquivos/pdf/revistainclusao1.pdf. Acesso em: 5 set. 2010.

SANTOS, Boaventura de Sousa. Reconhecer para libertar os caminhos do cosmopolitismo multicultural. Rio de Janeiro: Civilização Brasileira, 2003.

SASSAKI, R. K. Inclusão: construindo uma sociedade para todos. 4. ed. Rio de Janeiro: WVA, 2002.

SIQUEIRA, I. M.; SANTANA, C. S. Propostas de acessibilidade para a inclusão de pessoas com deficiências no ensino superior. Revista Brasileira de Educação Especial, Marília, v. 16, n. 1, p. 127-136, jan./abr. 2010.

STAINBACK, S. Considerações contextuais e sistêmicas para a Educação Inclusiva. Revista de Educação Especial, Brasília, ano 2, n. 3, p. 8-18, dez. 2006.

STAINBACK, S.; STAINBACK, W. Inclusão: um guia para educadores. Porto Alegre: Artmed, 1999.

TONET, I. Educação, cidadania e emancipação humana. Ijuí: Unijuí, 2005.

UNIVERSIDADE ESTADUAL VALE DO ACARAÚ. Projeto Pedagógico de Curso Licenciatura em Pedagogia. Universidade Estadual Vale do Acaraú, Sobral - CE, 2018. 


\section{Como referenciar este artigo}

SOARES, Ana Cristina Silva, OLIVEIRA, Daniele Kelly Lima de e SOUSA, Maria Gorete de. Reflexões a partir da percepção dos discentes sobre inclusão e cotas para estudantes com deficiências no ensino superior. Doxa: Rev. Bras. Psico. e Educ., Araraquara, v. 21, n. 2, p. 226-240. e-ISSN: 2594-8385. DOI: https://doi.org/10.30715/doxa.v21i2.13090

Submetido em: 20/02/2019

Aprovado em: 20/07/2019

Publicado em: 01/08/2019 